University of Nebraska - Lincoln

DigitalCommons@University of Nebraska - Lincoln

Agronomy \& Horticulture -- Faculty Publications

Agronomy and Horticulture Department

$10-1925$

Investigations on The Root Habits of Plants

J. E. Weaver

University of Nebraska-Lincoln

Follow this and additional works at: https://digitalcommons.unl.edu/agronomyfacpub

Part of the Plant Sciences Commons

Weaver, J. E., "Investigations on The Root Habits of Plants" (1925). Agronomy \& Horticulture -- Faculty Publications. 436.

https://digitalcommons.unl.edu/agronomyfacpub/436

This Article is brought to you for free and open access by the Agronomy and Horticulture Department at DigitalCommons@University of Nebraska - Lincoln. It has been accepted for inclusion in Agronomy \& Horticulture -Faculty Publications by an authorized administrator of DigitalCommons@University of Nebraska - Lincoln. 


\section{INVESTIGATIONS ON THE ROOT HABITS OF PLANTS ${ }^{1}$}

\section{J. E. WEAvER}

Ten years ago, while studying the vegetation of semi-arid eastern Washington, interest in root studies was aroused because of the extensive root systems of the native species. Balsamorrhiza sagittata, the first plant excavated, is representative. The strong tap root reaches a depth of six feet, and very numerous branches run laterally to distances of about two feet. Further investigations in several other states showed that extensive root systems are the rule among grassland species. Andropogon hallii, with exceedingly well branched fibrous roots seven feet deep, is representative of many of the dominants. About ninety percent of the more important species are rooted well below the two-foot level, and not a few, such as Liatris punctata, extend to depths of fifteen to twenty-two feet.

The great extent of roots in relation to above-ground parts is often very striking. Gleditsia triacanthos, thirteen weeks after seed-germination, although reaching a height of only nine inches, produced a remarkably widespread root system that extended well into the fourth foot of soil. The roots of Solidago oreophila, a small species only about a foot high, spread about two feet on all sides of the plant while some penetrate downward to a distance of two and one half feet. Nor is the great extent of roots in comparison to tops confined to native species. Maize (Zea mays indentata) has a wonderfully developed root system which occupies rather thoroughly over two hundred cubic feet of soil. The root system of the sugar beet (Beta vulgaris) is likewise very extensive, branching widely and extending downward to a depth of five or six feet.

The rapidity of root growth is quite as remarkable as root extent. Spartina cynosuroides reaches a depth of over four feet at the age of eleven weeks. This growth rate of over half an inch a day is not unusual among our native grasses. The widely spreading roots of potatoes, when they begin their vertical descent, elongate at the rate of an inch a day for a period of two or more weeks. When the main vertical roots of corn begin to develop, they sometimes penetrate downward at the remarkable rate of 2 to 2.5 inches per day during a period of 3 or 4 weeks, sometimes reaching depths of more than eight feet. The rate of growth of the primary root system of winter wheat during I0- or I5-day intervals is of in terest (text fig. I). An average growth rate of over half an inch per day is maintained for a period of 70 days. Of course, during this time abundant laterals and also roots of the secondary system are developing.

${ }^{1}$ Invitation paper read at the joint meeting of Section G, American Association for the Advancement of Science, the Botanical Society of America, the American Phytopathological Society, and the American Society of Plant Physiologists at Washington, December 30, 1924. 
That large amounts of both water and nutrients are absorbed by these deeply penetrating roots has been repeatedly demonstrated. By means of wax seals placed at various depths in filling large containers, soil layers of known water and nutrient content have been effectually isolated from the layers above and below. Through these seals roots penetrate readily and

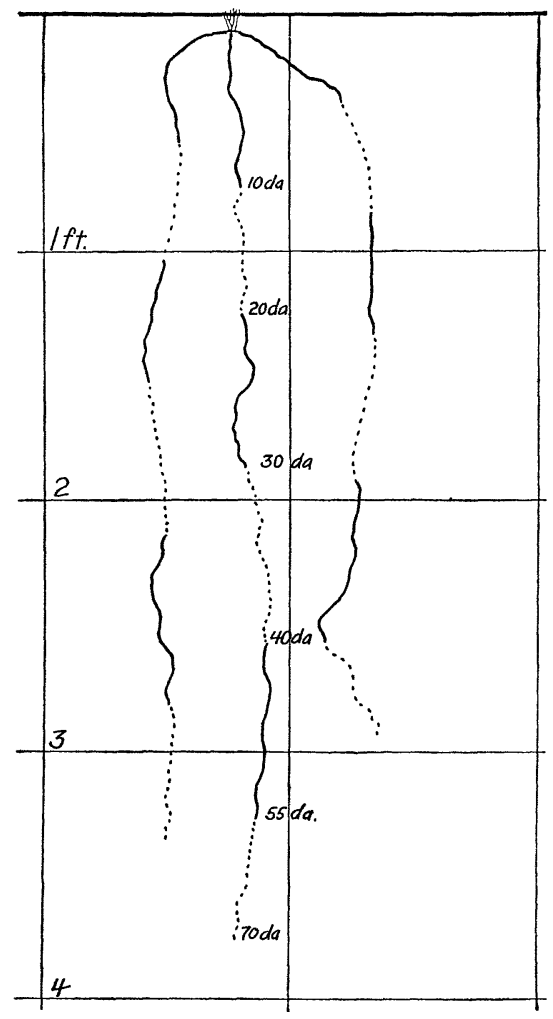

Text FIG. I. Diagram from field measurements showing the rate of growth of winter wheat during I0- and I5-day intervals.

develop normally. By this means it has been ascertained, for example, that barley absorbed I9 percent of water, based on the dry weight of the soil, from the first foot, $\mathrm{I} 6$ percent from the second, and $\mathrm{I} 3$ percent from the third, while I I percent was absorbed from the fourth foot of soil. Barley, like maize, absorbed large quantities of nitrates from the deeper soil. Maize removed 203 parts per million of nitrates from the third foot, I 40 from the fourth, and i 8 from the fifth.

Variations in root habit under different climatic conditions are often very pronounced. Continued examination of the smaller cereals in fertile siltloam soils under a wide range of precipitation and soil moisture shows that the root habit varies widely (text fig. 2). Under 26 to 32 inches of pre- 
cipitation, such as occurs in eastern Kansas and Nebraska, the tops of winter wheat are tall and the roots deep, but the lateral spread is relatively small. But in western Kansas and eastern Colorado, where 16 to 19 inches of precipitation wet the soil to only 2 to 2.5 feet, the tops are short, and the roots are shallow but very widely spreading and much more profusely branched. Root habit under an intermediate precipitation of $2 \mathbf{I}-24$ inches falls between

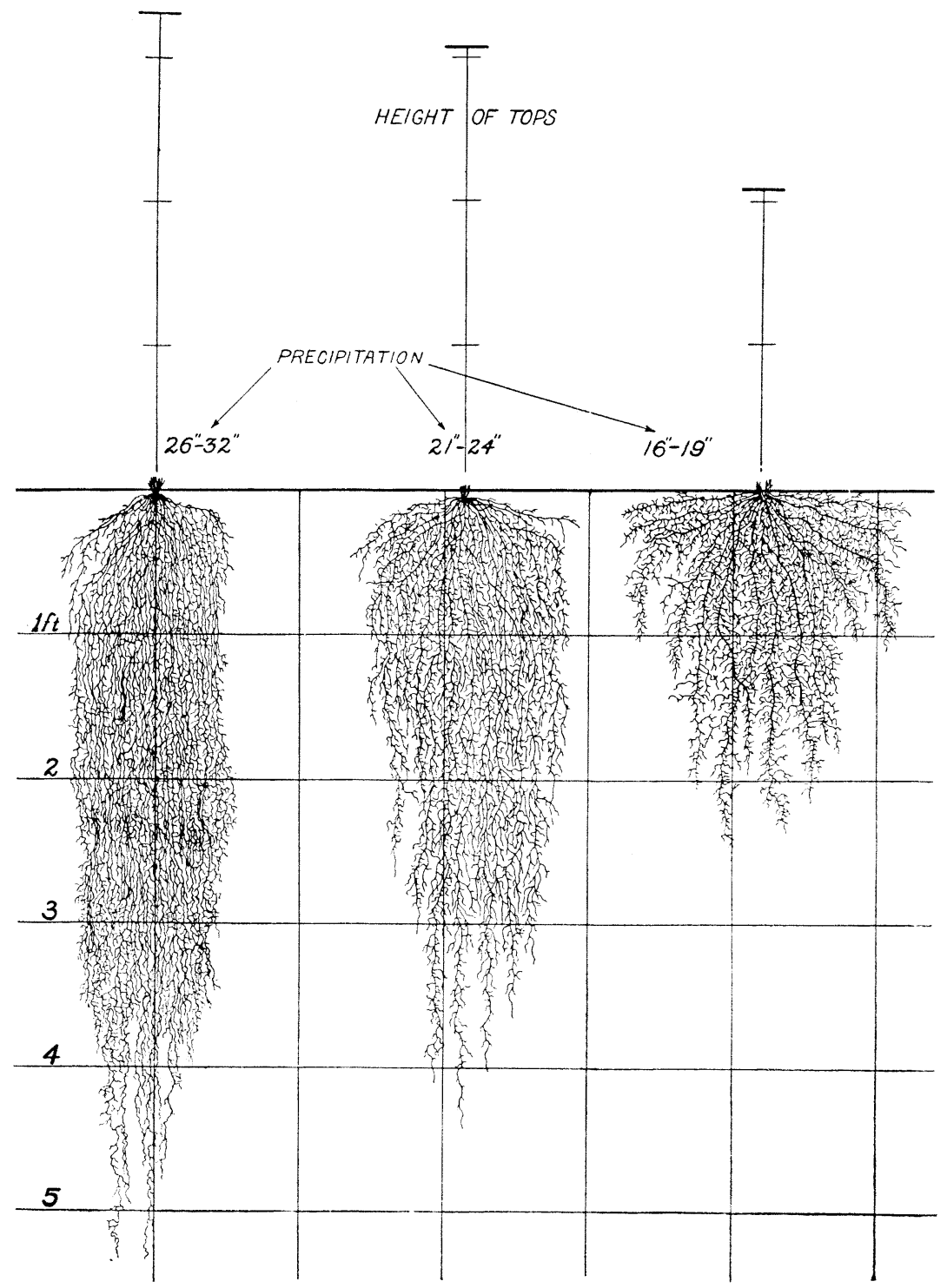

TExT Fig. 2. Diagram showing the growth of root and shoot of winter wheat in fertile silt-loam soil under different climates. 
these extreme types, but is correlated with a medium development of shoot. Two-year-old alfalfa, in fairly moist, deep soil, penetrates with little branching of the tap root to depths of from Io to 12 feet. But on the Great Plains, where a subsoil lacking available water prevents downward penetration, so many profusely branched, widely spreading laterals are produced that one would hardly recognize the roots as those of alfalfa.

Variations under local environments are also very great. The effects of the addition of nitrates, for example, in retarding root-elongation and promoting branching are well known. Sugar beets of the same age and grown in similar soil show marked differences. One plot was manured and irrigated, whereas in the other the soil was very dry and the deeper subsoil was almost without available water. Differences in root habit were shown in depth of penetration, and in number, length, and position of lateral branches. In the dry land the beets had their normally deeply penetrating tap roots limited because of dry subsoil in their early development to only one half the depth in the moist soil, and throughout the season they were I to $\mathbf{I} .5$ feet shorter. Branching was more profuse and sublaterals were more abundant than in fully irrigated soil.

Root-stratification due to soil texture is not infrequent. In one experimental plot, layers of clay occurred in the fine-sandy loam at depths of I6 inches and 3.5 feet respectively. Into these layers of greater nutrient content densely branched roots of sugar beet ran horizontally in great profusion, contrasting in a striking manner with the more poorly branched parts of the root system above and below.

Six-weeks-old maize grown in a fine-sandy loam with only 4 to 6 percent of available water had a very different root habit from that grown in an otherwise similar but manured soil with a nearly optimum water content. In the watered plot the roots were very near the surface, being almost entirely in the first 8 inches of soil. But in the unirrigated plot, where the surface soil was very dry and not so rich in nutrients, the roots penetrated more deeply and the branches were more than twice as numerous. Moreover, these laterals were double the length of those in the rich, moist soil and were clothed with approximately twice as many fine sublaterals.

Pronounced differences in root-development in the same field may also be induced by competition. Spring wheat grown at the normal field rate of planting was more deeply rooted when mature than wheat planted four times as thickly. The working levels were 39 and 35 inches respectively. But in proportion to tops, plants of the thicker stand had much more extensive root systems. Competition for water and nutrients had reduced the supply to such a degree that, although in adjoining plots, the thickly planted crop was growing in a much drier and less fertile soil. Root habits of sunflowers planted respectively 2,8 , and 32 inches apart were very different. The working levels of the tap roots were, in the preceding sequence, $5,6.5$, and 8 feet. Those of the numerous laterals were I2, 37, and 48 inches. 
Moreover, the lateral spread varied from to inches in the thickest plantings to 42 inches in the thinnest. Although the water content was about the same in all three plots throughout the season and the nitrates were constantly reduced to a minimum, yet the more widely spaced plants had more of both these essentials. Likewise, they had more light for food-manufacture, and the better top development afforded an abundance of food for root-building.

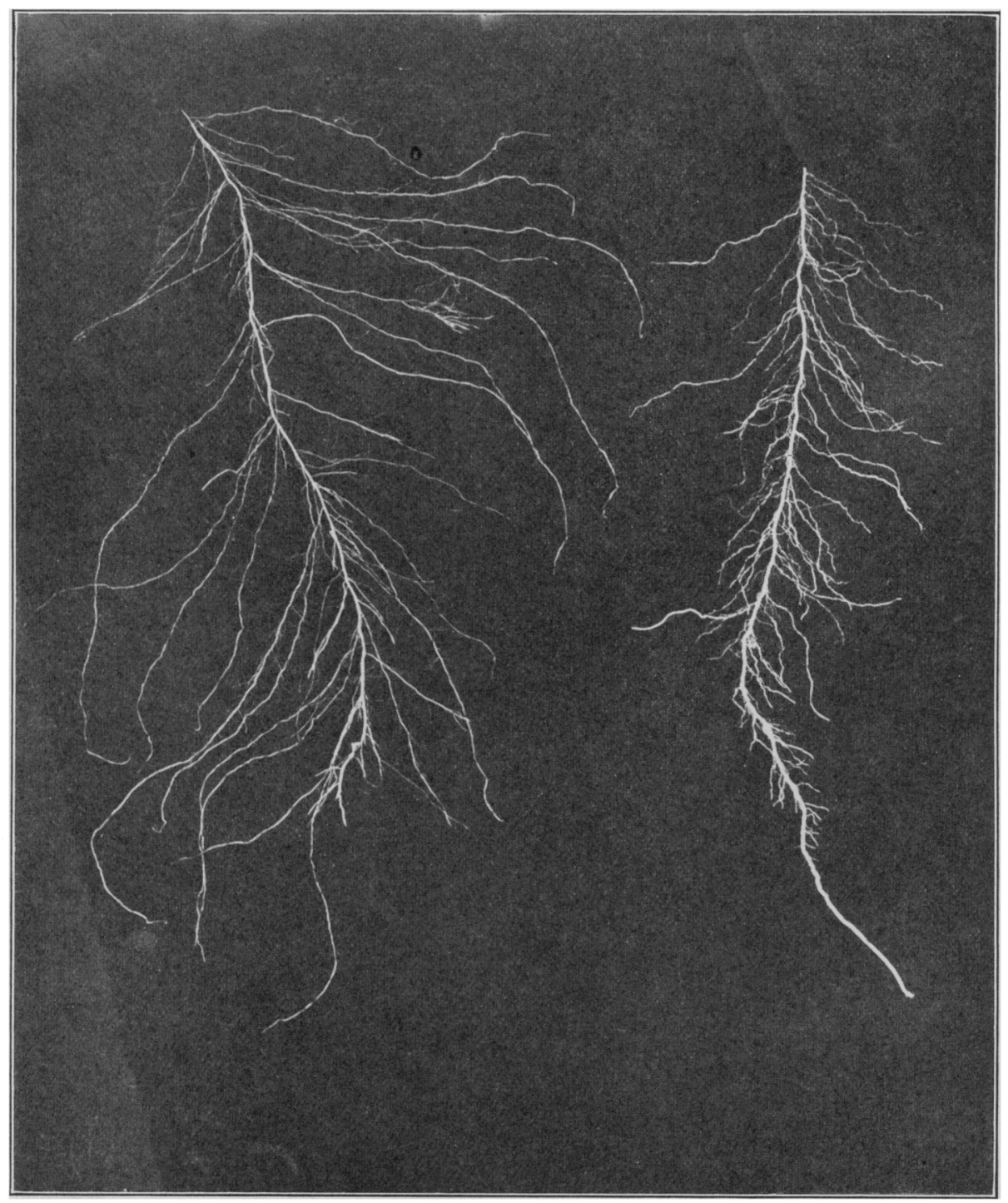

Text Fig. 3. Portions of the primary root system of maize; (left) from wet loess and (right) from moist sandy soil. 
However, when based either on leaf expanse or on dry weight of tops, the nitrogen-starved, dwarfed plants in the crowded environment had relatively a more extensive root-development.

Considerable progress has been made in a study of the relation of absorbing area to transpiring surface. Methods have been devised by means of which it has been found possible to secure root systems several feet in extent quite in their entirety from the soil in which they grew. Indeed, microscopic examination showed that the root tips of even the most delicate laterals were wholly intact. The large amount of work involved in securing and accurately measuring the surface of even a single root system may be partly appreciated when we find that a plant of maize only in the eighth-leaf stage has from 8,000 to 10,000 laterals arising from the 15 to 23 main roots.

Nebraska White Prize corn of the $\mathrm{F}_{1}$ generation from two pure-line parental strains, and consequently of similar hereditary constitution, was grown for 5 weeks in fertile loess soil at water contents of 9 and I9 percent respectively above the hygroscopic coefficient. In the wet soil the area of the tops (including the stem and counting both surfaces of the leaves) was 82 percent of that of the roots. But in the drier soil the tops had only 46 percent as great an area as the roots. In other words, the absorbing area of the roots (exclusive of root hairs-which covered the entire system but which, of course, were not measured) was I.2 times as great as the area of tops in the wet soil and 2.2 times as great in the drier soil. The total length of the main roots in the two cases was about the same, as was also their diameter. In neither case did the main roots make up more than I I percent of the total absorbing area. In the drier soil 75 percent of the area was furnished by the primary laterals and the remaining I4 percent by branches from these. But in the wet soil the primary branches furnished only 38 percent of the root area. It seemed as though the plant had blocked out a root system quite inadequate to meet the heavy demands for absorption made by the vigorous top, and the remaining $5^{\mathrm{I}}$ percent of the area was furnished by an excellent development of secondary and tertiary branches.

The large area of a single root is of ten impressive. Text figure 3 (left) shows about two thirds of the primary root of corn from wet soil. This portion had an area of 132 square centimeters, or only slightly less than one third of the area of this page. In fact, the three roots of the primary system constituted 49 percent of the entire absorbing area.

Plants in loess soil with only 2 to 3 percent of water in excess of the hygroscopic coefficient had, in proportion to the length of the main roots, about one third more laterals than those in a similar soil of medium water content. Moreover, the absorbing area, in comparison to tops, was greater.

Corn grown in sandy soil, with an optimum water supply but a higher nitrate content than the loess, had an intermediate root area (text fig. 3 , right). It was I.3 times as great as the area of the above-ground parts. 
Aside from the Io percent total absorbing area furnished by its main roots, the remainder was divided almost equally between primary and secondary laterals, no tertiary branches occurring.

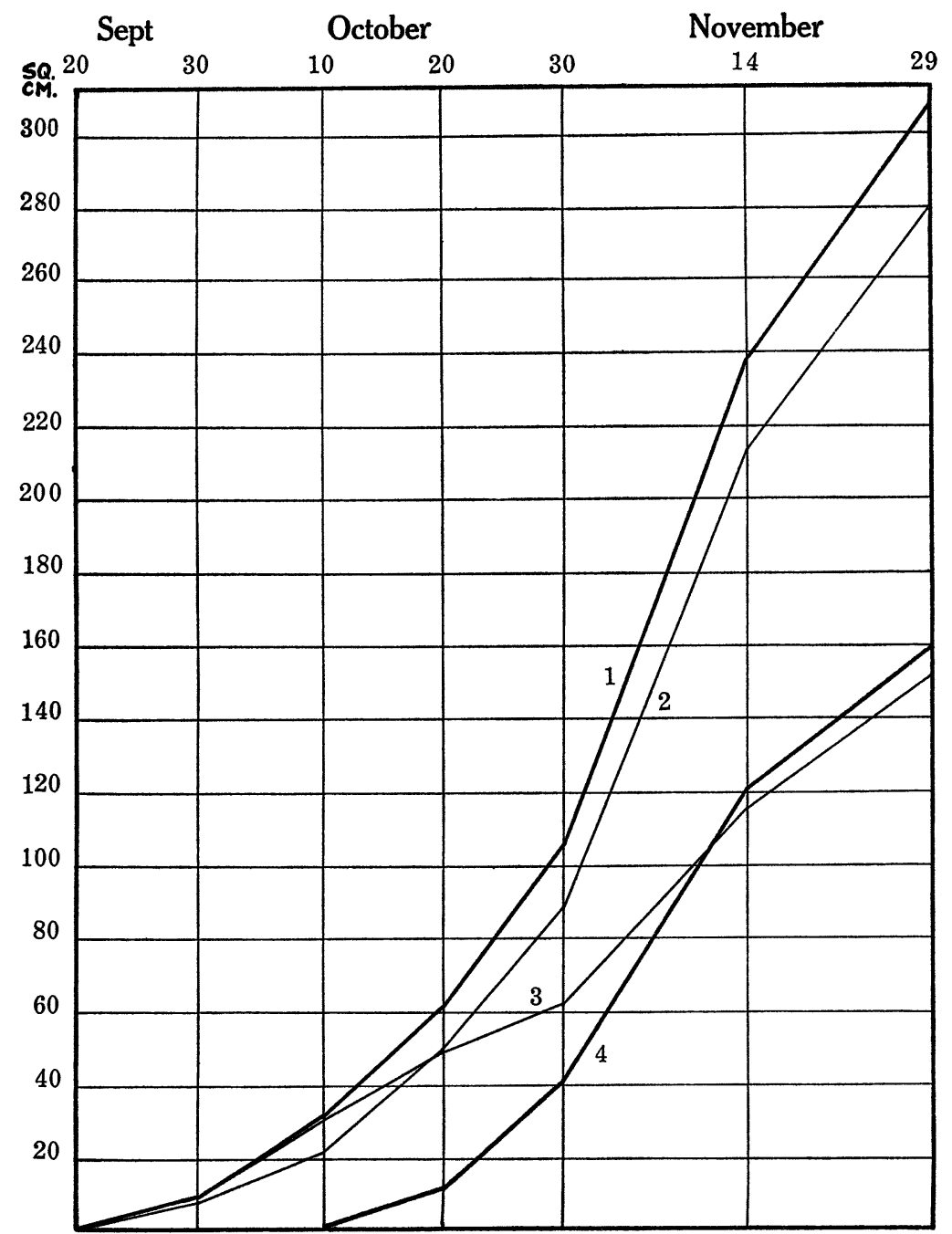

TexT FIg. 4. Graphs showing: I, the absorbing area of winter wheat (exclusive of root hairs); 2, the photosynthetic and transpiring area; 3 , the absorbing area of the primary root system; 4, the absorbing area of the secondary root system.

The relation between the area of roots and the area of tops of a variety of Turkey Red winter wheat grown under field conditions has been determined at intervals of Io to I5 days (text fig. 4). Graph I shows the root area at the end of the several periods, graph 2 the area of the above-ground parts at the same times. The parallelism of the two graphs is very striking, as is also 
the continuously greater root-absorbing surface compared to the photosynthetic and transpiring area. Root area exceeded area of shoot by to to 35 percent. Graph 3 shows the proportion of the entire absorbing surface (exclusive of root hairs) furnished by the primary root system; and graph 4 the part afforded by the secondary root system. The rapidity of the development of the latter is marked, exceeding at the end of 35 days of its growth the area of the primary root system. Another feature was the persistence of functioning root hairs. Not until 7 weeks after planting did the root hairs begin to slough off from even the oldest part of the primary roots, and 3 weeks later all but one third of one percent of the entire root area was clothed with functioning root hairs. Of course in very dry soils these are shorter-lived and many of the branch roots from which they arise may also die.

Adaptation of crop plants to new environments whether by selection or by breeding, like so many other problems in plant-production, warrants careful study of root relations.

UNIVERSITY OF NEBRASKA 